\title{
Effect of head and neck radiotherapy on the Eustachian tube functions
}

\author{
Ahmed Abdullah Hamd ${ }^{1 *}$ (D), Essam Abd El-Wanes Behiry ${ }^{2}$, Adel Tharwat Atallah², Sherif Maher Elaini ${ }^{3}$ and \\ Ahmed Hamdy Alshafai ${ }^{2}$
}

\begin{abstract}
Background: Nowadays, radiotherapy is widely used in management of many types of tumors including head and neck tumors; in this study, we concerned with its reverse effects on the Eustachian tube functions and if this effect is temporary or permanent.

Results: The whole (30) patients have tympanogram at both ears before starting radiotherapy; all patients (100\%) were normal. In the immediate post radiotherapy tympanogram at the contralateral side, $6.7 \%$ of patients had effusion, and 20\% had Eustachian tube dysfunction, while at the ipsilateral side, 20\% of patients had effusion, and 33.3\% had ET dysfunction. In the follow-up tympanogram 12 weeks post radiotherapy, we found that $6.7 \%$ of patients had effusion, and (10\%) had Eustachian tube dysfunction at the contralateral side, while $6.7 \%$ of patients had effusion, and only 20\% had Eustachian tube dysfunction at the ipsilateral side.

Conclusion: From this study, we concluded that patients with head and neck tumors treated by radiotherapy (apart from the nasopharynx) have a high incidence of affection of Eustachian tube function namely middle ear effusion and Eustachian tube dysfunction. The possibility for development of middle ear effusion and Eustachian tube dysfunction increases with increased tumor stage. Eustachian tube functions immediately post radiotherapy and after 12 weeks of the end of radiotherapy was affected by different effects according to the tumor site. The Eustachian tube functions significantly improved within 12 weeks after the last dose of radiotherapy, and we recommend audiological follow-up for patients with head and neck tumors treated with radiotherapy.
\end{abstract}

Keywords: Tympanometry, Eustachian tube function test, Radiotherapy

\section{Background}

Radiation is widely used in treatment of many types of tumors including head and neck tumors and the increasing proportion of patients who survive the disease; physicians should be aware of the risks of radiation on their patients. In this review, we discussed the pathophysiology of radiation injuries to the soft tissue of the temporal bone especially the Eustachian tube. In this study, our aim is to evaluate the effect of radiotherapy (RT) as one of the modalities of treatment in patients with head and neck tumors on the Eustachian tube functions at the ipsilateral and contralateral ears.

\footnotetext{
* Correspondence: Ahmedhamd8869@gmail.com

${ }^{1}$ Faculty of Medicine, Alazhar University, Cairo, Egypt

Full list of author information is available at the end of the article
}

\section{Patients and methods}

This is a prospective study of thirty patients ( 28 males and 2 females) with age ranging between 48 and 71 years with head or neck tumors or both which required radiotherapy as a main line or adjuvant line of treatment. The study was conducted in a prospective manner during the period from February 2019 to February 2020. All the patients have tympanometry (before, immediately after, 12 weeks post) radiotherapy using tympanogram.

\section{Patient selection and pretreatment tumor work-up}

Patients suffering only from head and neck tumors were included in our study. Carcinomas of the nasopharynx were excluded from the study. Patients were subjected to careful history taking and complete otolaryngological

\section{Springer Open}

(๑) The Author(s). 2020 Open Access This article is licensed under a Creative Commons Attribution 4.0 International License, which permits use, sharing, adaptation, distribution and reproduction in any medium or format, as long as you give appropriate credit to the original author(s) and the source, provide a link to the Creative Commons licence, and indicate if changes were made. The images or other third party material in this article are included in the article's Creative Commons licence, unless indicated otherwise in a credit line to the material. If material is not included in the article's Creative Commons licence and your intended use is not permitted by statutory regulation or exceeds the permitted use, you will need to obtain permission directly from the copyright holder. To view a copy of this licence, visit http://creativecommons.org/licenses/by/4.0/. 
and head and neck examination. Computed tomography of the neck was performed for the assessment of the primary tumor as well as the neck nodes. Direct laryngoscopy under general anesthesia was performed for mapping the tumor and biopsy taking for histopathological examination. The primary tumor and the neck were classified on the basis of physical examination, computed tomography, and endoscopic findings. According to the site and TNM staging of the tumor, patients were offered either surgery and postoperative RT or primary RT alone or concomitant CRT.

\section{Lines of treatment}

Radiotherapy is the main line of treatment even alone or adjuvant line. $43.3 \%$ of patients received radiotherapy alone, and $56.7 \%$ received radiotherapy and surgery treatment, with an average total dose of radiation of $65.8 \pm 3.7$ Gy (Table 1).

Radiotherapy doses were 60 to 70 Gy divided on 5 days weekly at a period between 6 and 8 weeks, and the radiotherapy technique used with all patients is external beam radiotherapy, where the linear accelerator (Linac), namely the source of radiation, is placed outside the patient and beams of radiation are delivered to a specific area of the patient's body. This method is called 3-dimensional conformal radiotherapy (3DCRT). The target or tumor volume (the disease) is modeled and the radiations are directed to this volume. Tympanometry study for the patient was selected to evaluate the ET functions as it was the most reliable, available, easy to perform, and gave objective data needed to evaluate the ET tympanometry study performed preexposure to radiotherapy and repeated immediately after full dose of radiotherapy and then 12 weeks after the last exposure to radiotherapy for all patients for comparison.

\section{Statistical analysis}

Data entry, processing, and statistical analysis were carried out using MedCalc ver. 18.2.1 (MedCalc, Ostend, Belgium). Tests of significance (ANOVA and chi-square tests) were used. Data were presented, and suitable analysis was done according to the type of data (parametric and nonparametric) obtained for each variable. $p$ values less than $0.05(5 \%)$ was considered to be statistically significant.

\section{Results}

This was a prospective study conducted on 30 patients with head or neck tumors to evaluate the effect of

Table 1 Lines of treatment

\begin{tabular}{lll}
\hline Variables & Frequency (\%) \\
\hline Line of treatment & Radiotherapy alone & $13(43.3 \%)$ \\
& Radiotherapy + surgery & $17(56.7 \%)$ \\
\hline
\end{tabular}

radiotherapy in patient with head and neck tumors on the Eustachian tube (ET).

\section{Site of tumor}

There were 20 patients $(66.7 \%)$ with glottic carcinoma, 3 patients (10\%) with supraglottic carcinoma, 3 patients (10\%) with post cricoid carcinoma, 2 patients (6.7\%) with tongue squamous cell carcinoma, and 2 patients $(6.7 \%)$ with parotid adenocarcinoma.

\section{Tumor stage and nodal stage}

There were 7 patients $(23.3 \%)$ of $\mathrm{T} 1,16$ patients $(53.3 \%)$ of T2, 6 patients $(20 \%) \mathrm{T} 3$, and 1 patient $(3.3 \%)$ of T4. Nineteen patients $(63.3 \%)$ were N0, 5 patients $(16.7 \%)$ were N1, 5 patients $(16.7 \%)$ were $\mathrm{N} 2$, and 1 patient (3.3\%) was N3.

\section{Tumor side}

In our study, there were 20 patients with left side tumor (18 laryngeal and 2 parotid tumors) and there were 10 patients with right side tumor (8 laryngeal and 2 tongue tumors).

\section{Comparative study according to tumor site}

Tympanogram findings at immediate post radiotherapy at glottic, sub glottic, supra glottis, parotid, and tongue tumors revealed a significant increase in ipsilateral ET dysfunction in sub and supra glottic groups, compared with the glottic group, with a significant statistical difference $(P=0.037)$ and revealed non-significant difference as regards contralateral ET dysfunction $(p>0.05)$. Tympanogram findings after 12 weeks post radiotherapy revealed a non-significant difference as regards ipsilateral and contralateral ET dysfunction $(p>0.05)$. (Table 2$)$

\section{Follow-up tympanogram (Tables 3 and 4)}

\section{Discussion}

Radiotherapy is commonly used either alone as a primary treatment or in combination with surgery and or chemotherapy for the treatment of malignant tumors of head and neck but it has many side effects. This study was conducted among 30 patients (60 ears) with laryngeal, parotid, and tongue cancer. In this study, we focused on the audiological sequelae of radiotherapy through Eustachian tube function using tympanogram. And we were concerned with this effect if it is temporary or permanent. And we were interested to know if this radiotherapy effect is related to the site of the tumor or not. Through our study, we have found the following.

\section{Tympanometry immediate post radiotherapy findings}

As a result of radiotherapy, the Eustachian tube was affected by radiation leading to otitis media with effusion or ET dysfunction. Bursary et al. [1] noted radiation otitis media as an early and transient change following ionizing 
Table 2 Comparison between the 3 groups as regards follow-up tympanogram data using chi-square test

\begin{tabular}{|c|c|c|c|c|c|}
\hline Variable & & $\begin{array}{l}\text { Glottic } \\
\text { group } \\
\text { (20) }\end{array}$ & $\begin{array}{l}\text { Sub- } \\
\text { glottic } \\
\text { group } \\
\text { (3) }\end{array}$ & $\begin{array}{l}\text { Supra- } \\
\text { glottic } \\
\text { group } \\
\text { (7) }\end{array}$ & $\begin{array}{l}\text { Chi-square test } \\
p \text { value }\end{array}$ \\
\hline Tympanogram before treatment in both ears & Normal & $20(100 \%)$ & $3(100 \%)$ & $7(100 \%)$ & \\
\hline \multirow[t]{3}{*}{ Tympanogram (end of ttt) (contralateral) } & A-Normal & $15(75 \%)$ & $3(100 \%)$ & $4(57.1 \%)$ & $=0.3761$ \\
\hline & B-Effusion & $2(10 \%)$ & $0(0 \%)$ & $0(0 \%)$ & \\
\hline & C-ET dysfunction & $3(15 \%)$ & $0(0 \%)$ & $3(42.9 \%)$ & \\
\hline \multirow[t]{3}{*}{ Tympanogram (end of ttt) (ipsilateral) } & A-Normal & $10(50 \%)$ & $1(33.3 \%)$ & $3(42.9 \%)$ & $=0.037^{*}$ \\
\hline & B-Effusion & $2(10 \%)$ & $0(0 \%)$ & $4(57.1 \%)$ & \\
\hline & C-ET dysfunction & $8(40 \%)$ & $2(66.7 \%)$ & $0(0 \%)$ & \\
\hline \multirow[t]{3}{*}{ Tympanogram (12 weeks) (contralateral) } & A-Normal & $16(80 \%)$ & $3(100 \%)$ & $6(85.7 \%)$ & $=0.8160$ \\
\hline & B-Effusion & $2(10 \%)$ & $0(0 \%)$ & $0(0 \%)$ & \\
\hline & C-ET dysfunction & $2(10 \%)$ & $0(0 \%)$ & $1(14.3 \%)$ & \\
\hline \multirow[t]{3}{*}{ Tympanogram (12 weeks) (ipsilateral) } & A-Normal & $15(75 \%)$ & $2(66.7 \%)$ & $5(71.4 \%)$ & $=0.0744$ \\
\hline & B-Effusion & $0(0 \%)$ & $0(0 \%)$ & $2(28.6 \%)$ & \\
\hline & C-ET dysfunction & $5(25 \%)$ & $1(33.3 \%)$ & $0(0 \%)$ & \\
\hline
\end{tabular}

*Percentage of Column Total

radiation to the head and neck. They explained the mechanism by obstruction of the Eustachian tube due to swelling of the mucosa following irradiation resulting first in the absorption of the oxygen then later the nitrogen from the middle ear. Because of the negative pressure in the middle ear cavity, transduction can take place which is enhanced by the edema of the middle ear mucosa and the dilatation of the blood vessels resulting in sterile fluid collection in the middle ear cavity.

Post radiotherapy tympanometry was done immediately after the end of treatment and revealed that $40 \%$ of the patients developed abnormal tympanometry findings which were $13.3 \%$ as type $B$ tympanogram and $26.7 \%$ as type $\mathrm{C}$ tympanogram. Bohne et al. [2] conducted a similar study and reported $48 \%$ abnormal tympanometry findings among their patients where $15 \%$ had serous middle ear effusion with type B tympanogram and 33\% had Eustachian tube dysfunction with type $\mathrm{C}$ tympanogram. They also stated that the incidence of serous middle ear effusion declined 3 months after radiotherapy while Eustachian tube dysfunction persisted.

Bhandare et al. [3] found a $28.6 \%$ incidence of 2 weeks post radiotherapy middle ear toxicity and Eustachian tube

Table 3 Tympanogram (before, at end of treatment, and after 12 weeks) among 30 patients

\begin{tabular}{|c|c|c|}
\hline \multicolumn{2}{|l|}{ Variables } & \multirow{2}{*}{$\begin{array}{l}\text { Frequency (\%) } \\
30(100 \%)\end{array}$} \\
\hline Tympanogram (before ttt) (ipsilateral and contralateral) & A-Normal & \\
\hline & B-Effusion & $0(0 \%)$ \\
\hline & C-ET dysfunction & $0(0 \%)$ \\
\hline \multirow[t]{3}{*}{ Tympanogram (end of ttt) (contralateral) } & A-Normal & $22(73.3 \%)$ \\
\hline & B-Effusion & $2(6.7 \%)$ \\
\hline & C-ET dysfunction & $6(20 \%)$ \\
\hline \multirow[t]{3}{*}{ Tympanogram (end of ttt) (ipsilateral) } & A-Normal & $14(46.7 \%)$ \\
\hline & B-Effusion & $6(20 \%)$ \\
\hline & C-ET dysfunction & $10(33.3 \%)$ \\
\hline \multirow[t]{3}{*}{ Tympanogram (12 weeks) (contralateral) } & A-Normal & $25(83.3 \%)$ \\
\hline & B-Effusion & $2(6.7 \%)$ \\
\hline & C-ET dysfunction & $3(10 \%)$ \\
\hline \multirow[t]{3}{*}{ Tympanogram (12 weeks) (ipsilateral) } & A-Normal & $22(73.3 \%)$ \\
\hline & B-Effusion & $2(6.7 \%)$ \\
\hline & C-ET dysfunction & $6(20 \%)$ \\
\hline
\end{tabular}


Table 4 Eustachian tube functions according to dose of radiotherapy

\begin{tabular}{|c|c|c|c|c|c|}
\hline Dose & $\begin{array}{l}\text { Tympano before } \\
\text { radiography at } \\
\text { both ears }\end{array}$ & $\begin{array}{l}\text { Tympano after } \\
\text { radiotherapy at } \\
\text { ipsilateral ear }\end{array}$ & $\begin{array}{l}\text { Tympano after } \\
\text { radiotherapy at } \\
\text { contralateral ear }\end{array}$ & $\begin{array}{l}\text { Tympano } 12 \text { weeks after } \\
\text { radiotherapy at ipsilateral } \\
\text { ear }\end{array}$ & $\begin{array}{l}\text { Tympano } 12 \text { weeks after } \\
\text { radiotherapy at contralateral } \\
\text { ear }\end{array}$ \\
\hline $60 \mathrm{GY}$ & $\begin{array}{l}\text { Bil type A } \\
14 \text { ears (23.3\%) }\end{array}$ & $\begin{array}{l}\text { A (normal) } 4(57.1 \%) \\
\text { B (effusion) } 1(14.3 \%) \\
\text { C (ETD) } 2 \text { (28.6\%) }\end{array}$ & $\begin{array}{l}\text { A (normal) } 5(71.4 \%) \\
\text { B (effusion) } 0(0 \%) \\
C \text { (ETD) } 2(28.6 \%)\end{array}$ & $\begin{array}{l}\text { A (normal) } 5(71.4 \%) \\
\text { B (effusion) } 1(14.3 \%) \\
\text { C (ETD) } 1(14.3 \%)\end{array}$ & $\begin{array}{l}\text { A (normal) } 7(100 \%) \\
\text { B (effusion) } 0(0 \%) \\
\text { C (ETD) } 0(0 \%)\end{array}$ \\
\hline $66 \mathrm{GY}$ & $\begin{array}{l}\text { Bil type } A \\
28 \text { ears }(46.7 \%)\end{array}$ & $\begin{array}{l}\text { A (normal) } 6(42.9 \%) \\
\text { B (effusion) } 2(14.2 \%) \\
\text { C (ETD) } 6 \text { (42.9\%) }\end{array}$ & $\begin{array}{l}\text { A (normal) } 10(71.4 \%) \\
\text { B (effusion) } 1(7.1 \%) \\
\text { C (ETD) } 3(21.3 \%)\end{array}$ & $\begin{array}{l}\text { A (normal) } 9(64.4 \%) \\
\text { B (effusion) } 1(7.1 \%) \\
C \text { (ETD) } 4(28.5 \%)\end{array}$ & $\begin{array}{l}\text { A (normal) } 11 \text { (78.7\%) } \\
\text { B (effusion) } 1(7.1 \%) \\
\text { C (ETD) } 2(14.2 \%)\end{array}$ \\
\hline $70 \mathrm{GY}$ & $\begin{array}{l}\text { Bil type } A \\
18 \text { ears (30\%) }\end{array}$ & $\begin{array}{l}\text { A (normal) } 4(44.5 \%) \\
\text { B (effusion) } 3(33.3 \%) \\
\text { C (ETD) } 2 \text { (22.2\%) }\end{array}$ & $\begin{array}{l}\text { A (normal) } 7 \text { (77.8\%) } \\
\text { B (effusion) } 1 \text { (11.1) } \\
\text { C (ETD) } 1(11.1 \%)\end{array}$ & $\begin{array}{l}\text { A (normal) } 8(88.9 \%) \\
\text { B (effusion) } 0(0 \%) \\
\text { C (ETD) } 1(11.1 \%)\end{array}$ & $\begin{array}{l}\text { A (normal) } 7(77.8 \%) \\
\text { B (effusion) } 1(11.1 \%) \\
\text { C (ETD) } 1(11.1 \%)\end{array}$ \\
\hline
\end{tabular}

affection which included radiation otitis media, otitis media with effusion, and Eustachian tube dysfunction. They stated middle ear complication post radiotherapy to the head and neck as the most common complication.

The post radiotherapy tympanometry findings were abnormal in $40 \%$; this would point to the observations of the high prevalence of Eustachian tube affection among patients treated by radiotherapy.

In a similar study by Christiane et al. [4], the tympanometric curve was normal in $75.0 \%$ (abnormal in 25.0\%) of the ears in the group of individuals exposed to radiotherapy and normal in $95.0 \%$ of the ears in the control group (not exposed to radiotherapy).

Although statistically insignificant, in supraglottic carcinomas, 3 of 3 have abnormal tympanogram. This is mostly due to high incidence of nodal metastasis in supraglottic carcinoma so that the nodes at risk are treated bilaterally in conjunction with the primary malignancy and so large field of irradiation. The fields usually extend from the bottom of the cricoid cartilage to 1 to $2 \mathrm{~cm}$ above the angle of the mandible. However, larger samples are needed to detect effect of radiotherapy on tumors of this site. In the analysis for the influence of tumor stage, nodal stage, and tumor site on the middle ear function, only the tumor site had a statistical influence on the tympanogram findings $(p=0.04)$.

The tympanogram was significantly $(p=0.04)$ affected by the advancement of the tumor; this is because as the size of the tumor increases, and the field used for local control likewise increases, the risk of injury to normal tissue becomes greater.

Leach [5] reported that radiotherapy on head and neck tumors developed many complications according to the radiated anatomical area; in other words, they depend on the area (radiotherapy field) where the radiation is being deployed.

Pearson et al. [6] reported that head and neck radiotherapy has ototoxic effects which involve whole the ear especially at the same side of irradiation.

Ana et al. [7] study reported that especially for advanced disease, because of the presence of large tumors, there is a need to irradiate the primary site of the disease and those areas suspected of microscopic disease, having potential side effects as consequences, especially on the healthy tissue near the tumor site.

Bhandare et al. [3] study reported that ototoxicity after RT is a significant complication in a subset of patients who receive high doses to the auditory apparatus. The incidence of ototoxicity in all parts of the auditory system increases with total dose significantly above 60 to 66 Gy but may be observed at doses as low as 50 Gy. Chemoradiation and fractionation may contribute to the incidence of ototoxicities.

\section{Radiotherapy as a main line of treatment}

In the analysis for the influence of radiotherapy on the middle ear function, there was no statistical influence on the tympanogram findings nor on the Eustachian tube function.

Maier et al. [8] investigated Eustachian tube function before and after surgery and radiotherapy of patients suffering from carcinoma of the larynx or hypopharynx and reported that there were no significant alterations of tubal function after neck dissection with or without surgery of the primary tumor, but he observed a significant deterioration of the tubal function immediately after a series of fractionated percutaneous telecobalt therapy (60 Gy).

\section{Dose of irradiation and its affection on Eustachian tube functions}

In spite of being statistically insignificant, higher doses cause more affection, so it is better to treat patients with novel radiotherapy techniques, to enable escalating the radiotherapy doses given to advanced tumors and simultaneously reducing the doses to healthy normal tissues, thus significantly improving the therapeutic ratio of radiotherapy.

Evans et al. [9] concluded in a study made on 58 patients of histologically proven carcinoma of head and neck which received external beam radiotherapy that the dose of the radiation is proportional to the development of ototoxicity. Total radiation dose of minimum $60 \mathrm{~Gy}$ is required to produce noticeable ototoxic effects.

In Ana et al. [7] study, according to results from their statistical analysis, they did not observe a significant association regarding complications after treatment for patients who received radiation doses higher than 64 Gy. 


\section{Tympanometry after 12 weeks post radiotherapy}

A point of value was to know if the radiotherapy effect on the Eustachian tube was permanent or temporary; data analysis between baseline, end of treatment, and 12 weeks tympanograms revealed a significant increase in contralateral ET dysfunction at end of treatment (20\%) and 12 weeks followup $(10 \%)$, with a significant difference $(p=0.011)$. Comparative analysis between baseline, end of treatment, and 12 weeks tympanograms revealed highly significant increase in ipsilateral ET dysfunction at end of treatment (33.3\%) and 12weeks follow-up (20\%), with a highly significant difference $(p=0.001)$. This means that there is significant improvement at Eustachian tube dysfunction by the time, and the effect of radiotherapy is not a permanent effect.

In our study, we were concerned with the relation of tumor site, and its relation to Eustachian tube dysfunction occurred due to exposure to radiotherapy; we found that the site of the tumor has a significant element (as the ipsilateral ear usually affected more than the contralateral one), as the nasopharyngeal carcinoma was excluded from our study which proved to have a higher incidence of OME and ET dysfunction at the contralateral side of RT exposure.

On the other hand, we were concerned whether the effect of radiotherapy is permanent or not, but we found a significant improvement of the ET function after 12 weeks after the end of radiotherapy.

\section{Conclusion}

Patients with head and neck tumors treated by radiotherapy apart from the nasopharynx have a high incidence of affection of Eustachian tube functions; the possibility for development of Eustachian tube affection increases with increased tumor stage which usually required higher dose of radiation (T4 patients receive $70 \mathrm{GYs}$ ).

Tumor site has significant difference at Eustachian tube affection (due to late discovering of supra and sub glottis tumors which usually have metastatic lymph nodes at the neck, so the exposed area to radiotherapy is larger and dose is higher) immediately post radiotherapy and after 12 of the end of radiotherapy. The middle ear functions significantly improved within 12 weeks after the last dose of radiotherapy.

Tumor side also has significant difference at Eustachian tube affection (ipsilateral ears of radiation were more affected than contralateral ones due to selective neck dissection and parotid radiotherapy which increases the incidence of ipsilateral ear affection).

\section{Abbreviations}

3DCRT: 3-dimensional conformal radiotherapy; CRT: Chemoradiotherapy; ET: Eustachian tube; Gy: Gray; RT: Radiotherapy

\section{Authors' contributions}

EB analyzed and interpreted the patient data regarding the tumor site and grade. AT performed the direct laryngoscopic examination and biopsy taken. SM followed up the patients with serial tympanometry before, immediate after, and 12 weeks post radiotherapy. AH observed the data collection and interpretation to reach to the results. AA collected the data and followed up the patients and was a major contributor in writing the manuscript. All authors read and approved the final manuscript.

\section{Funding}

The study was funded indirectly by a cooperation between Al-Maadi Military Complex and Menoufia University Hospitals' departments of oncology, radiology, and audiology.

\section{Availability of data and materials}

The study was conducted in a prospective manner during the period from February 2019 to February 2020 on 30 patients with head or neck tumors or both which required radiotherapy as a main line or adjuvant line of treatment referred from the ENT department of al-Maadi Medical Complex and university hospital; both radiotherapy and audiological evaluations were done at the oncology and audiology departments of the same hospitals. Finally, the datasets analyzed during the current study are available from the corresponding author on reasonable request.

\section{Ethics approval and consent to participate}

This study was approved by the ethics committee of Menoufia University with approval number 253/2019. The patients provided written consents, and the ethics committee approved this procedure.

\section{Consent for publication}

Consents from the patients have been taken before the study, and all gave us written consents.

\section{Competing interests}

All the authors declare that they have no competing interests in this section.

\section{Author details}

${ }^{1}$ Faculty of Medicine, Alazhar University, Cairo, Egypt. ${ }^{2}$ Faculty of Medicine, Menoufia University, Shibin Al Koum, Egypt. ${ }^{3}$ Military Medical Academy, Cairo, Egypt.

Received: 22 May 2020 Accepted: 23 September 2020

Published online: 21 October 2020

\section{References}

1. Bursary S, Blanchard G, Borsanyi SJ, Blanchard CL (1962) lonizing radiation and the ear. JAMA. 181:958-961

2. Bohne BA, Marks JE, Glasgow GP (1985) Delayed effects of ionizing radiation on the ear. Laryngoscope $95: 818-828$

3. Bhandare N, Antonelli PJ, Morris CG, Malayapa RS, Mendenhall WM (2007) Ototoxicity after RT for head and neck tumors. Int J Radiat Oncol Biol Phys 67:469-479

4. Schultz C, Valeria M, Goffi-Gomez S, Helena P, Liberman P, Cassio A, Carvalho AL (2010) Hearing loss and complaint in patients with head and neck cancer treated with radiotherapy. Arch Otolaryngol Head Neck Surg. https://doi.org/10.1001/archoto.2010.180

5. Leach W (1965) Irradiation of the ear. J Laryngol Otology 79(10):870-880. https://doi.org/10.1017/S0022215100064495

6. Pearson SE, Meyer AC, Adams GL, Ondrey FG (2006) Decreased hearing after combined modality therapy for head and neck cancer. Am J Otolanngol 27(2):76-80

7. Dell'Aringa AHB, de Lima Isaac M, Arruda GV, Dell'Aringa AR, Esteves MCBN (2010) Audiological findings in patients treated with radiotherapy for head and neck tumors. Brazil J Otorhinolaryngol 76:527-532

8. Maier H, Gewelke U, Dietz A, Heller WD (1992) Risk factors of cancer of the larynx: results of the Heidelberg case-control study. Orolaryngol Head Neck Surg 107(4):577-582

9. Evans RA (1988) Assessment of the permanent hearing impairment following radical megavoltage RT. J Laryngol Otol 102:588-589

\section{Publisher's Note}

Springer Nature remains neutral with regard to jurisdictional claims in published maps and institutional affiliations. 